\title{
Association between migration status and caesarean section delivery based on a modified Robson classification in China
}

Ming Liu ${ }^{1,2+}$, Mengqi Xue ${ }^{1 \dagger}$, Qing Yang ${ }^{3}$, Wenchong Du ${ }^{4}$, Xiaoling Yan², Jing Tan², Tao Duan ${ }^{2 \dagger}$ and Jing Hua ${ }^{{ }^{*}}$

\begin{abstract}
Background: China has one of the highest caesarean section (C-Section) rates in the world. In recent years, China has been experiencing a massive flow of migration due to rapid urbanization. In this study, we aimed to differentiate the rates of C-Section between migrants and residents, and explore any possible factors which may moderate the association between migrant status and C-Section rates.

Methods: We conducted a retrospective cohort study in Shanghai, China. All deliveries were classified using the modified Robson Classification. The association between women's migrant status and C-Section rates was assessed using the Poisson regression of sandwich estimation, after adjusting for possible factors.

Results: Of the 40,621 women included in the study, $66.9 \%$ were residents and $33.1 \%$ were internal migrants. The rate of C-Section in migrants was lower than that of residents in all subjects (39.9 and 47.7\%) and in group 1 subjects (based on the Robson Classification) using a modified Robson Classification. There was an association between migrant status and caesarean delivery on maternal request that was statistically significant $(\mathrm{RR}=0.664, p<$ 0.001), but the association was weakened after adjusting for such factors as maternal age at delivery $(a R R=0.774$, $p=0.02)$, ethnicity ( $\mathrm{aRR}=0.753, p<0.001)$, health insurance ( $\mathrm{aRR}=0.755, p<0.001)$, and occupation $(\mathrm{aRR}=0.747$, $p=0.004$ ), but had no significant changes when adjusting for health conditions ( $a R R=0.668, p=0.001$ ) and all considering variables (aRR $=0.697, p=0.002$ ). In group 1 subjects, the effect of migrant status on maternal requested intrapartum C-Section was also statistically significant $(R R=0.742, p=0.004)$.
\end{abstract}

Conclusion: C-Section rates are lower among migrant women than residents, especially on maternal request. The medical practitioners should further reinforce the management of elective C-Section in resident women.

Keywords: Caesarean section rate, Modified Robson classification, Residents and internal migrants, China

\footnotetext{
*Correspondence: szhuaj@hotmail.com

${ }^{\dagger}$ Ming Liu, Mengqi Xue and Tao Duan contributed equally to this work.

'The Women and Children's Health Care Department, Shanghai First

Maternity and Infant Hospital, Tongji University School of Medicine, Shanghai 200000, China

Full list of author information is available at the end of the article
}

(C) The Author(s). 2021 Open Access This article is licensed under a Creative Commons Attribution 4.0 International License, which permits use, sharing, adaptation, distribution and reproduction in any medium or format, as long as you give appropriate credit to the original author(s) and the source, provide a link to the Creative Commons licence, and indicate if changes were made. The images or other third party material in this article are included in the article's Creative Commons licence, unless indicated otherwise in a credit line to the material. If material is not included in the article's Creative Commons licence and your intended use is not permitted by statutory regulation or exceeds the permitted use, you will need to obtain permission directly from the copyright holder. To view a copy of this licence, visit http://creativecommons.org/licenses/by/4.0/ The Creative Commons Public Domain Dedication waiver (http://creativecommons.org/publicdomain/zero/1.0/) applies to the data made available in this article, unless otherwise stated in a credit line to the data. 


\section{Background}

Caesarean section (C-Section) rates are reported to be associated with higher rates of maternal morbidity and mortality compared to vaginal births [1]. The World Health Organization (WHO) guidelines have deemed CSection rates of $10-15 \%$ as justifiable [2]. C-Section rates of over $15 \%$ can lead to increased risks for reproductive health outcomes, which outweigh the benefits of $\mathrm{C}$ Section [3]. However, a large number of countries nowadays have $\mathrm{C}$-Section rates that are much higher than the WHO recommendation [3]. China is one of the countries that have a dramatic increase in caesarean section rates in recent years $[4,5]$. A survey from WHO showed that China's average annual caesarean delivery rate of $46.2 \%$ was the highest among nine Asian countries from 2007 to 2008 [6]. Another study involving more than 30 million showed that the C-Section rate in China was $32.7 \%$ from 2008 to 2014 [7].

Except for the medical reasons for conducting a CSection, it has been reported that $\mathrm{C}$-Section rates varied across populations with different socio-demographic status [8-10]. A meta-analysis based on 76 studies reported that there was a difference in caesarean rates between migrants and non-migrants in over $69 \%$ of studies [11]. However, this result seemed to conflict with the lower C-Section rates in migrants compared with residents, and there is limited evidence to explain these differences in C-Section rates. Frequently suggested factors that may explain the lower C-Section rates in migrants include younger pregnancy age, healthy immigrant effect, preference for a vaginal birth, and a healthier lifestyle $[12,13]$. In contrast, commonly suggested factors for the higher $\mathrm{C}$-Section rates in migrants are poverty, unemployment, low social status, and inadequate prenatal care, among others [14, 15].

China has experienced a massive internal population migration in recent years due to the rapid urbanization process, and the healthcare situation of migrants in China can be more complicated. In China, it can be difficult for migrants to obtain permanent residency in urban areas due to the regulations imposed by the government. In Shanghai, $40.3 \%$ of the total population was comprised of internal migrants in 2012 [16]. It has been reported that the internal migrants often face numerous social adversities, [11, 17-19] which may influence their C-Section rates [11, 17-19]. For instance, internal migrants often have a lack of social welfare benefits and/or health insurance, and therefore they are less likely to choose the more expensive C-Section procedure without medical indications. Furthermore, the demography of internal migrants consists of mainly blue-collar workers or housewives, which may be related to the healthy 'migrant' effect and the preference for vaginal delivery [20].
To our knowledge, few studies have reported on the $\mathrm{C}$-Section rates between internal migrants and residents in China. Here we conducted a retrospective cohort study in one of the largest maternity hospitals in Shanghai (Eastern Branch of Shanghai First Maternity and Infant Hospital), with approximately 15,000 deliveries per year. We hypothesized that the migrants may experience different $\mathrm{C}$-Section rates compared to residents. Additionally, in order to get a comprehensive picture of the $\mathrm{C}$-Section rates in residents and migrants, we used a modified Robson classification system and divided the subjects into ten groups with distinct obstetric features to assess the respective C-Section rates. The objects of the study were to: (1) assess the C-Section rates in both internal migrants and permanent residents based on the modified Robson ten-group classification system, (2) analyze the effects of migrant status on a caesarean section on maternal request (CSMR), and explore the mediating or moderating factors (especially the sociodemographic factors under Chinese context) which may affect the association between migrant status and CSection, to provide evidence-based clues in reducing the high rates of $\mathrm{C}$-Section in China.

\section{Methods \\ Participants}

We conducted a retrospective cohort study in Eastern Branch of Shanghai First Maternity and Infant Hospital - one of the largest maternity hospitals in China. A total of 41,295 live births (birth weight $>500 \mathrm{~g}$ ) were recorded between January 1st of 2012 to September 30th of 2014 in the hospital's electronic database. Most of the variables such as ethnicity, health insurance, occupation, and health condition, were collected retrospectively from the hospital's electronic medical record registration system. Three variables including previous C-Section, induction of labour, and delivery by C-Section before labour, and the indications of C-Section were manually retrieved from printed medical records at the time of birth. A total of 346 (0.84\%) women had to be excluded due to the missing items in electronic medical birth records (such as ethnicity, health insurance, occupation, and health condition). And 328 (0.79\%) women were excluded due to missing information about three variables (women with previous C-Section, labour induced, and delivered by C-Section before labour) when we manually collected from printed medical records. Finally, a total of 40,621 live births with complete records were included in the final study.

\section{Measurement \\ Exposure}

We categorized the participants into "residents" and "internal migrants". Different from the residents, internal 
migrants refer primarily to migrants within China without local household registration status through the Chinese Hukou system [21, 22]. Internal migrants are most excluded from local educational resources, citywide social welfare programs and many jobs because of their lack of hukou status.

\section{Outcomes}

The Robson classification system was proposed by examining C-Section within mutually exclusive groups of women with particular obstetric characteristics on the basis of five parameters: obstetric history (parity and previous caesarean section), number of neonates, gestational age (preterm or term), the onset of labour (spontaneous, induced, or caesarean section before the onset of labour), and fetal presentation or lie (cephalic, breech, or transverse). Although the Robson classification scheme has been widely accepted by the international community, it is necessary to revise in several categories for current guidance in obstetric practice. For example, the modified classification [23] separates the intrapartum C-Section after induction of labour and prelabour CSection because the original Robson classification may miss the important information of the high C-Section rate reduced by the induction of labour which was common in present obstetric population especially in China. Additionally, the modified classification scheme combined the three groups of breech (by parity) and transverse or oblique into one, because the total number of non-cephalic presentation births accounts very small proportion and the vaginal delivery with the non-cephalic presentation is no longer promoted in many countries including China nowadays.

The cesarean section on maternal request (CSMR) is defined as a primary cesarean delivery at maternal request in the absence of any medical or obstetric indication [24-26]. The medical indications for C-Section (MICS) were defined according to the Chinese expert consensus [27], which included the complications of labor and factors increasing the risk associated with vaginal delivery and other complications of pregnancy, pre-existing conditions, and concomitant disease need immediate termination of pregnancy.

\section{Other variables}

The following socio-demographic factors which may moderate the association between migrant status and CSection rate were included in our study. We categorized the ethnicity into 'Han' and 'others' because the majority of the Chinese population belong to Han ethnicity. We divided the maternal age into three age bands of ' $<20$ ', ' 20 to 34 ', and ' $\geq 35$ '. The health insurance was dichotomized into 'yes' or 'no'. We categorized the occupation into 'Non-managerial position', 'Managerial position',
'Unemployed' and 'Workers (conducting physical labor) or others according to their personal information on the electronic medical record registration system.

There were several adverse health conditions that were not (or not severe enough to be) absolute contraindications to vaginal delivery according to the Chinese expert consensus but considered as moderating factors in our study [27]. Pre-pregnancy BMI is calculated according to the mother's height and pre-pregnancy weight. Based on the literature, we categorized maternal BMI into '< 18.5 '(underweight), '18.5 to 24.9 '(normal weight), and ' $\geq 25$ ' (overweight) according to the WHO BMI classification, [28] and neonatal birth weight into $<2500 \mathrm{~g}^{\prime}$ (low birth weight),' $2500 \mathrm{~g}$ to $3999 \mathrm{~g}$ '(normal birth weight) and ${ }^{\prime} \geq 4000$ g' (macrosomia). Hypertensive disorder complicating pregnancy was defined as systolic pressure over $140 \mathrm{mmHg}$ or diastolic blood pressure over $90 \mathrm{mmHg}$. Gestational diabetes mellitus (GDM) was defined as blood glucose levels above $5.1 \mathrm{mmol} / \mathrm{L}$ at fasting, 10.0 $\mathrm{mmol} / \mathrm{L}$ at $1 \mathrm{~h}$ or $8.5 \mathrm{mmol} / \mathrm{L}$ at $2 \mathrm{~h}$ by oral glucose tolerance test. Other maternal complications included maternal renal diseases, HIV infections, prenatal fever. The renal diseases are defined as patients already impaired renal function except for hypertension at the start of gestation. Prenatal fever was diagnosed when the body temperature was higher than $38^{\circ} \mathrm{C}$ twice in a row before delivery. Positive HIV (human immunodeficiency virus) antibody throughout pregnancy was diagnosed HIV infections, including AIDS and asymptomatic infections. Other fetal complications included fetal abnormalities and small for gestational age. The fetal malformation is defined as a structural or functional defect caused by abnormal development of an embryo or fetus. A newborn is considered as Small for gestational age (SGA) when birth weight and length below the 10th percentile for gestational age [29].

\section{Statistical analysis}

We calculated the differences of $\mathrm{C}$-Section rate, and the medically indicated and maternal requested C-Section rates between residents and migrants using the Pearson Chi-square test. We also calculated the C-Section rate, and the medically indicated and maternal requested CSection rates in each group based on the modified Robson classification using Chi-square test. Additionally, differences in demographics, C-Section rates, and indications between migrants and residents were assessed using Pearson Chi-square analysis. Were analyzed using the Pearson Chi-square test and post-hoc comparison.

The associations between women's migrant status and C-Section rates were estimated when adjusting for possible moderators or mediators (socio-demographics, complications, and other health conditions) or not adjusting for any variables. Relative Risk (RR) was estimated 
using a modified Poisson regression approach (Poisson regression with a robust error variance). Application of Poisson regression on multi-nominal data has been shown to overestimate for the relative risk [30,31]. We rectified this using the robust error variance procedure known as sandwich estimation, in our modified Poisson regression [30] using PROC GENMOD in SAS 9.2 software. A $p$-value of $<0.05$ was considered statistically significant.

\section{Results}

Of the 40,621 women included in the final analysis, $66.9 \%$ were residents and $33.1 \%$ were migrants. There was a difference in $\mathrm{C}$-Section rates between residents $(47.7 \%)$ and migrants $(39.9 \%)(p<0.001)$. In addition, there was a difference in CSMR rates between resident and migrant women $(20.0 \%$ vs. $15.3 \%, p<0.001)$, as well as a difference in MICS rates between resident and migrant women $(27.6 \%$ vs. $24.6 \%, p<0.001)$. When we divided the subjects into ten groups according to the modified Robson classification (Table 1), only subjects in group 1 (Nulliparous women with a single cephalic pregnancy, at $\geq 37$ weeks of gestation in spontaneous labour) had higher $\mathrm{C}$-Section rates in residents compared to that of migrant women with statistical significance $(p=$ 0.005). There were also differences in C-Section rates (with or without medial indications) between residents and migrants in group 1 subjects $(p=0.015$, Table 1$)$. The CSMR rates in residents were higher than that of migrants in group 7 (Nulliparous women with a single cephalic pregnancy, at $\geq 37$ weeks of gestation, who had caesarean section before labour) and group 8 (Multiparous women, without a uterine scar, with a single cephalic pregnancy at $\geq 37$ weeks of gestation, who had caesarean section before labour) with no statistical significance. We also did not observe the differences in CSection rates between residents and migrant women in other groups $(p>0.05$, Table 1$)$.

Table 2 showed the differences in age, ethnicity, occupation, and health conditions between residents and migrant women and among different delivery modes in all subjects and group 1 subjects using the modified Robson Classification. The distributions of detailed health conditions by migrant status and delivery mode were showed in Additional file 1: Table 1. We further analyzed the association between migrant status and C-Section rates (with or without medical indications), and explored the potential factors which may mediate or moderate the above associations (Table 3). In all subjects, migrants were less likely to undergo C-Section when there were no medical indications, compared to residents ( $R R=$ $0.664, p<0.001)$. The protective effects weakened after adjustment for such factors as maternal age at delivery ( $\mathrm{aRR}=0.774, p=0.02)$, ethnicity $(\mathrm{aRR}=0.753, p<0.001)$, health insurance $(\mathrm{aRR}=0.755, p<0.001)$, and occupation
( $\mathrm{aRR}=0.747, p=0.004)$, but had no significant changes when adjusting for health conditions $(\mathrm{aRR}=0.668$, $p=0.001$ ) and all potential variables which were considered in our study ( $\mathrm{aRR}=0.697, p=0.002$ ). The migrant status also had protective effects on MICS $(R R=0.776, p<0.001)$. However, there were no significant changes after adjusting for socio-demographic characteristics $\quad(\mathrm{aRR}=0.706 \sim 0.824$, each $p<0.01)$ health conditions $(\mathrm{aRR}=0.787, p<0.001)$ and all potential variables $(\mathrm{aRR}=0.770, p<0.001)$.

In women from group 1 of the modified Robson Classification, the effects of migrant status on CSMR were evident $(\mathrm{aRR}=0.742, p=0.004)$, and changed slightly after adjusting for demographic variables $(\mathrm{aRR}=0.730 \sim$ 769 , each $p<0.05$ ), health conditions ( $\mathrm{aRR}=0.744, p=$ $0.024)$, and all potential variables $(\mathrm{aRR}=0.728, p=0.009)$. However, there were no associations between migrant status and MICS ( $\mathrm{aRR}=0.885, p=0.308)$, and was only marginally significant after adjusting for health conditions $(\mathrm{aRR}=0.718, p=0.043)$, and all potential variables $(\mathrm{aRR}=$ $0.767, p=0.024$ ). The association between migrant status and C-Section rates after adjusting for adverse health conditions was showed in Additional file 1: Table 2.

\section{Discussion}

The present study sheds light on the effect of migrant status on C-Section rates in urban China based on a modified Robson ten-group Classification [23]. In our study, we observed a lower C-Section rate in migrants than that of permanent residents $(39.3 \%$ vs. $47.7 \%)$ in Shanghai city. The rate of CSMR of migrants was lower than residents in total subjects (15.3\% vs $20.0 \%)$, and in low-risk women with spontaneous labour $(2.4 \%$ vs $3.1 \%)$. Protective effects of migrant status on C-Section rates has been found on migrant women both with and without medical indications. Interestingly, our results showed that the effect of migrant status on CSMR was moderated by socio-demographic factors (age, ethnicity, health insurance, and occupation). However, in low-risk women with spontaneous labour, the socio-demographics did not mediate or moderate the association between the migrant status and intrapartum C-Section without medical indications.

We observed a lower rate of CSMR in migrants than that of residents. This result was consistent with previous studies, [11, 17-19] which showed that the CSection rate in migrant women was much lower than that of local residents in several other countries. For example, a prior study involving 9026 women from northern Italy showed that the C-Section rates in Italian immigrants were lower compared to permanent residents (27.4 and $37.1 \%$ respectively) [18]. Additionally, when the subjects in our study were divided into ten groups according to the modified Robson Classification, 


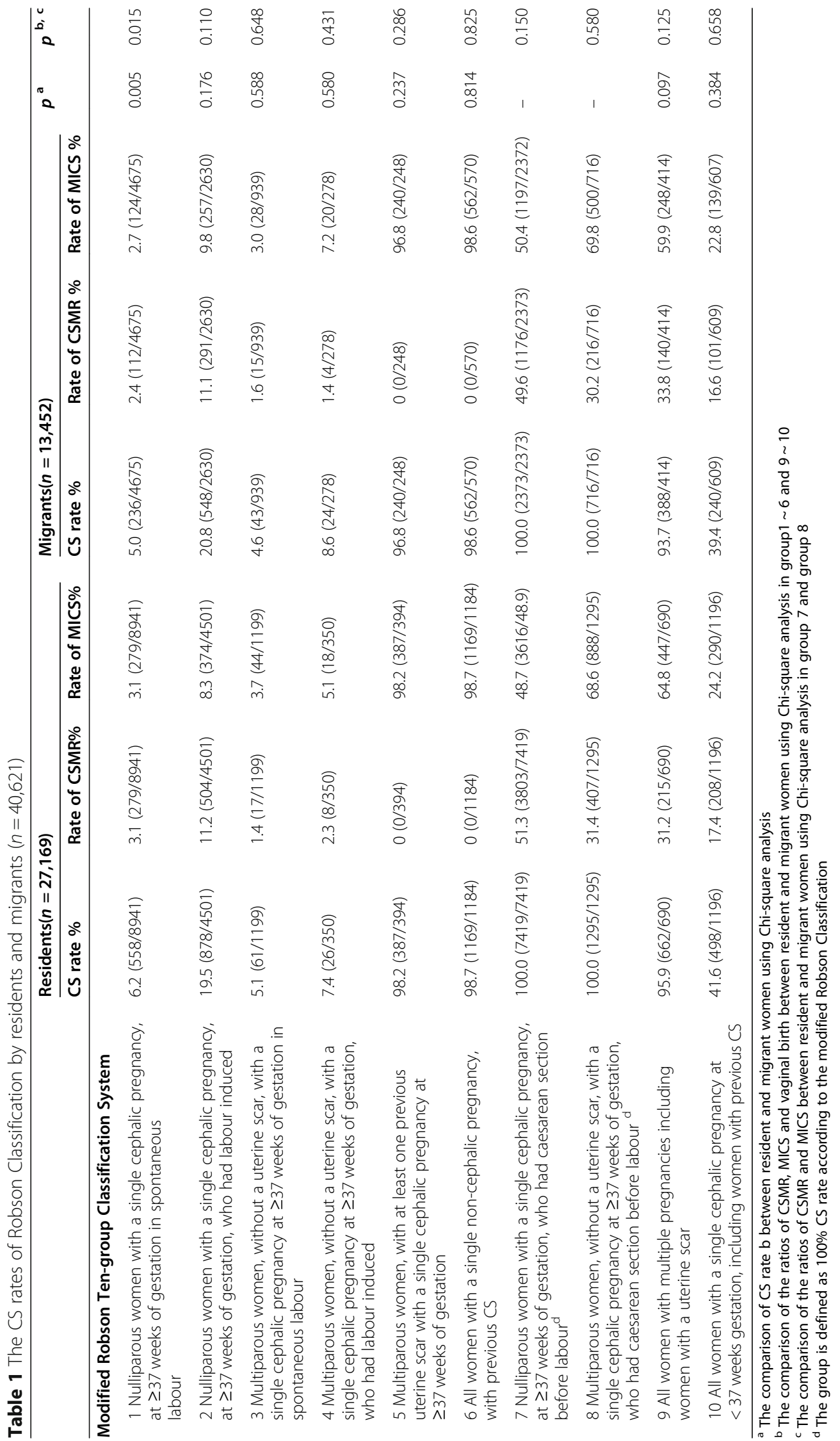




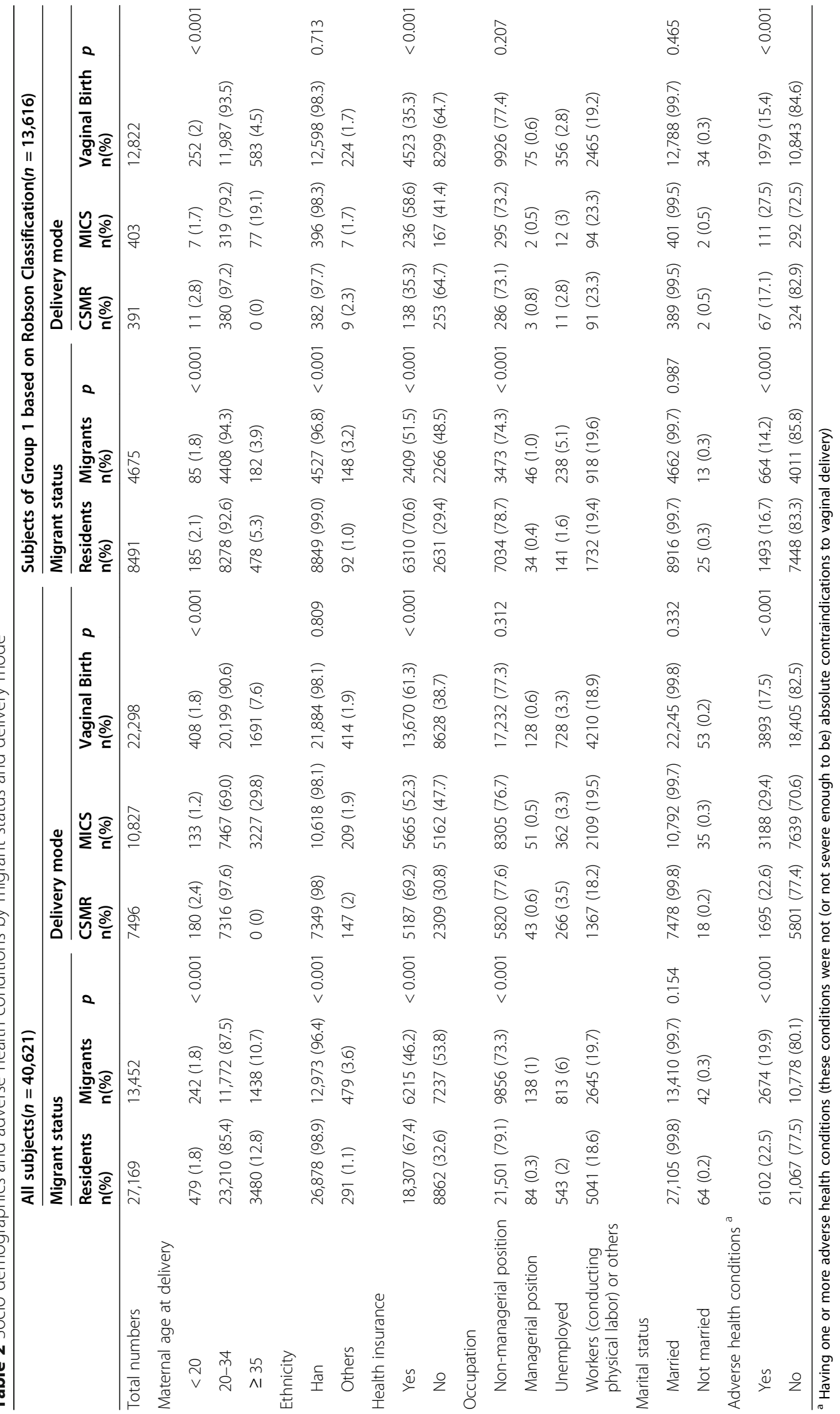


Table $\mathbf{3}$ The association between migrant status and CS rates

\begin{tabular}{|c|c|c|c|c|c|c|}
\hline \multirow[t]{2}{*}{ The adjusted variables } & \multicolumn{2}{|c|}{ CSMR vs vaginal birth } & \multirow[b]{2}{*}{$p$} & \multicolumn{3}{|c|}{ MICS vs vaginal birth } \\
\hline & Residents & $\begin{array}{l}\text { Migrants } \\
\text { RR }(95 \% \mathrm{Cl})\end{array}$ & & Residents & $\begin{array}{l}\text { Migrants } \\
\text { RR }(95 \% \mathrm{Cl})\end{array}$ & $p$ \\
\hline \multicolumn{7}{|l|}{ All subjects ( $n=40,621)$} \\
\hline Crude $^{a}$ & Ref & $0.664(0.627,0.704)$ & $<0.001$ & Ref & $0.776(0.739,0.815)$ & $<0.001$ \\
\hline Adjusted for maternal age at delivery & Ref & $0.774(0.747,0.802)$ & 0.002 & Ref & $0.824(0.783,0.867)$ & $<0.001$ \\
\hline Adjusted for ethnicity & Ref & $0.753(0.725,0.779)$ & $<0.001$ & Ref & $0.774(0.737,0.813)$ & $<0.001$ \\
\hline Adjusted for health insurance & Ref & $0.755(0.727,0.785)$ & $<0.001$ & Ref & $0.706(0.671,0.743)$ & 0.001 \\
\hline Adjusted for occupation & Ref & $0.747(0.726,0.780)$ & 0.004 & Ref & $0.773(0.736,0.812)$ & 0.003 \\
\hline Adjusted for adverse health conditions ${ }^{\mathbf{b}}$ & Ref & $0.668(0.631,0.708)$ & 0.001 & Ref & $0.787(0.749,0.827)$ & $<0.001$ \\
\hline Adjusted for all above variables & Ref & $0.697(0.657,0.740)$ & 0.002 & Ref & $0.770(0.731,0.812)$ & $<0.001$ \\
\hline \multicolumn{7}{|l|}{$\begin{array}{l}\text { Subjects of Group } 1 \text { based on Robson } \\
\text { Classification }(n=13,616)\end{array}$} \\
\hline Crude $^{a}$ & Ref & $0.742(0.605,0.910)$ & 0.004 & Ref & $0.885(0.699,1.120)$ & 0.308 \\
\hline Adjusted for maternal age at delivery & Ref & $0.769(0.626,0.945)$ & 0.012 & Ref & $0.873(0.690,1.105)$ & 0.259 \\
\hline Adjusted for ethics & Ref & $0.735(0.598,0.902)$ & 0.003 & Ref & $0.886(0.700,1.123)$ & 0.318 \\
\hline Adjusted for health insurance & Ref & $0.730(0.594,0.896)$ & 0.003 & Ref & $0.878(0.693,1.112)$ & 0.281 \\
\hline Adjusted for occupation & Ref & $0.737(0.601,0.905)$ & 0.004 & Ref & $0.877(0.693,1.110)$ & 0.275 \\
\hline Adjusted for adverse health conditions ${ }^{\mathbf{b}}$ & Ref & $0.744(0.607,0.914)$ & 0.024 & Ref & $0.718(0.564,0.913)$ & 0.043 \\
\hline Adjusted for all above variables & Ref & $0.728(0.580,0,915)$ & 0.009 & Ref & $0.767(0.602,0.978)$ & 0.024 \\
\hline
\end{tabular}

${ }^{a}$ Not adjusted for any variables

${ }^{b}$ Having one or more adverse health conditions (these conditions were not (or not severe enough to be) absolute contraindications to vaginal delivery)

the differences in C-Section rate between migrant and resident women were only seen among nulliparous women with a single cephalic term pregnancy with spontaneous onset of labour (group 1). The present CSection rates $(6.2$ and $5.0 \%$ in migrants and residents respectively) among nulliparous women with a single cephalic term pregnancy with spontaneous onset of labour (group 1) were slightly higher than the C-Section rates in a neighboring city (3.1-4.3\% in Nanjing) [32]. However, further study is needed to explore the related perinatal outcomes of C-Section based Robson Classification.

We further explored the potential moderate factors for the association between migrant status and C-Section rates. Interestingly, we found that the maternal sociodemographics (such as maternal age, ethnicity, health insurance, and occupation) moderated the effects of the migrant status on CSMR after adjusting for these factors. It has been reported that resident women were more likely to be elderly parturient nulliparous compared to their migrant counterparts [33]. Pregnant women over 34 years old were a major risk factor of high C-Section rates according to a previous study [34]. Therefore, the maternity age may moderate the association between migrant status and CSMR. Besides, the moderate effects of ethnicity on the association between migrant status and CSMR were likely caused by the one-child family policy [35]. This policy was only implemented in people of the Han nationality (ethnic majority) by the Chinese government, but not those of ethnic minorities in China. According to a previous study, [36] women under the one-child policy (even those with low-risk pregnancies) were more likely to have selective or elective C-Section in order to prevent their 'only' baby from being exposed to the risks that may result from obstetric complications during delivery.

Additionally, it has been reported that health insurance status independently affected elective C-Section [37] . The maternity insurance provided by the government is unfortunately not applicable for migrants in urban China [38]. Thus, these women were more likely to choose a 'cheaper' vaginal delivery when there was no medical indication of C-Section present. Moreover, according to our current study and previous studies, [38-40] the percentage of migrant women who did not have a job or only have a low-income job was significantly higher than that of residents. Compared with C-Section delivery, vaginal delivery means a shorter maternal length of stay in hospitals, [41] and paying less for medical care [42]. Therefore, migrants are less likely to select the more expensive operation when there were no medical indications for C-Section. However, it seems reasonable that the above factors (maternal age, ethnicity, health insurance, and occupation) have fewer moderate effects of migrant status on the rate of MICS.

However, in low-risk women with spontaneous delivery (group 1 of Robson Ten-group Classification), 
the association between migrant status and CSMR was only slightly moderated by maternal demographics and health conditions. The C-Section in women in this group usually occurred during intrapartum period (transfer from spontaneous delivery to C-Section) [43]. A systematic review found that fear of birth during pregnancy may sometimes lead to a request for a maternal requested caesarean birth [44]. Previous studies in China have reported that maternal anxiety, fear of labour pain, or perceived better health for the child and mother, are the main reasons for maternal requested intrapartum $\mathrm{C}$ Section [45-47].

\section{Conclusions}

C-Section rates (especially on maternal request) are lower among migrant women than residents, even in nulliparous women with a single cephalic pregnancy, at $\geq 37$ weeks of gestation in spontaneous labour. Our study provided evidence that the resident women should not be neglected for reducing the CSMR, and the medical practitioners should further reinforce the management of elective C-Section. Our study also provided the clues for policymakers to revise some of the strategies (e.g., the type of health insurance) to decrease the maternal requested C-Section. However, the difference is only partly explained by maternal background and health conditions. We did not record all fetal and maternal health conditions, and several socio-demographic factors, such as the migrants' hometown, a period of residency, and education backgrounds, which may also have an effect on the rates of C-Section [38]. Future studies are needed to investigate these factors in greater detail.

\section{Abbreviations}

C-Section: Caesarean sections; MCD: World health Organization (WHO); RR: Relative risk; Cl: Confidence interval

\section{Supplementary Information}

The online version contains supplementary material available at https://doi. org/10.1186/s12884-021-03708-6.

Additional file 1.

\section{Acknowledgements}

We thank Jie Mao \& Ting Luo for manually collecting some of the variables from papery medical records and Jun Zhang for revising the paper.

\section{Authors' contributions}

$\mathrm{ML}$ contributed to data collection and results interpretation. MX anticipated in the study design, data analysis, results interpretation and drafted the English version of the manuscript. XY, QY and JT participated in the study design, data collection, and results interpretation. WD participated in data analysis and drafted the English version of the manuscript. TD contributed to study design and results interpretation. JH participated in the study design, data analysis, result interpretation and drafted the English version of the manuscript. All authors have approved the manuscript and agree with submission to BMC Pregnancy and Childbirth.

\section{Funding}

This study was supported by National Natural Science Foundation of China (81673179), the Science and Technology Commission of Shanghai Municipality (18140903100), the Shenkang Hospital Development Center under Grant (SHDC12016239), Shanghai municipal medical and health discipline construction projects under Grant (2017ZZ02015). These funders had no any role in design of the study, data collection, analysis,

interpretation of the data and preparation of the manuscript.

\section{Availability of data and materials}

Data sets generated and/or analyzed during the current study available from the corresponding author on reasonable request.

\section{Declarations}

Ethics approval and consent to participate

The study received ethical approval from the Local Committee of Shanghai First Maternity and Infant Hospital, Tongji University School of Medicine, China (No. ks1785). The ethical committee has approved that the individual informed consent was not considered because almost all medical record data were collected at the institutional level without identifying the individuals.

\section{Consent for publication}

Not applicable.

\section{Competing interests}

The authors declare that they have no competing interests.

\section{Author details}

'The Women and Children's Health Care Department, Shanghai First Maternity and Infant Hospital, Tongji University School of Medicine, Shanghai 200000, China. ${ }^{2}$ The Obstetrical Department, Shanghai First Maternity and Infant Hospital, Tongji University School of Medicine, P.O. 536 Changle Road, Shanghai 200042, China. ${ }^{3}$ Songjiang Maternity \& Child Health Hospital of Shanghai, Shanghai 200042, China. ${ }^{4}$ Department of Psychology, Nottingham Trent University, Nottingham, UK.

Received: 8 February 2020 Accepted: 10 March 2021

Published online: 17 March 2021

\section{References}

1. Zwart JJ, Richters JM, Ory F, de Vries Jl, Bloemenkamp KW, van Roosmalen J. Severe maternal morbidity during pregnancy, delivery and puerperium in the Netherlands: a nationwide population-based study of 371,000 pregnancies. BJOG. 2008;115(7):842-50. https://doi.org/10.1111/j.1471-0528.2 008.01713.x.

2. Appropriate technology for birth. Lancet. 1985;2(8452):436-7.

3. Betran AP, Torloni MR, Zhang J, Ye J, Mikolajczyk R, Deneux-Tharaux C, Oladapo OT, Souza JP, Tuncalp O, Vogel JP, et al. What is the optimal rate of caesarean section at population level? A systematic review of ecologic studies. Reprod Health. 2015;12:57.

4. Tang CH, Wang HI, Hsu CS, Su HW, Chen MJ, Lin HC. Risk-adjusted cesarean section rates for the assessment of physician performance in Taiwan: a population-based study. BMC Public Health. 2006;6(1):246. https://doi.org/1 0.1186/1471-2458-6-246

5. Klemetti R, Che X, Gao Y, Raven J, Wu Z, Tang S, Hemminki E. Cesarean section delivery among primiparous women in rural China: an emerging epidemic. Am J Obstet Gynecol. 2010;202(1):65 e61-6.

6. Lumbiganon P, Laopaiboon M, Gulmezoglu AM, Souza JP, Taneepanichskul S, Ruyan P, Attygalle DE, Shrestha N, Mori R, Nguyen DH, et al. Method of delivery and pregnancy outcomes in Asia: the WHO global survey on maternal and perinatal health 2007-08. Lancet. 2010;375(9713):490-9. https://doi.org/10.1016/S0140-6736(09)61870-5.

7. Li HT, Luo S, Trasande L, Hellerstein S, Kang C, Li JX, Zhang Y, Liu JM, Blustein J. Geographic variations and temporal trends in cesarean delivery rates in China, 2008-2014. JAMA. 2017;317(1):69-76. https://doi.org/10.1001/ jama.2016.18663.

8. Nilsen C, Ostbye T, Daltveit AK, Mmbaga BT, Sandoy IF. Trends in and sociodemographic factors associated with caesarean section at a Tanzanian 
referral hospital, 2000 to 2013. Int J Equity Health. 2014;13(1):87. https://doi. org/10.1186/s12939-014-0087-1.

9. Gebremedhin S. Trend and socio-demographic differentials of caesarean section rate in Addis Ababa, Ethiopia: analysis based on Ethiopia demographic and health surveys data. Reprod Health. 2014;11(1):14. https:// doi.org/10.1186/1742-4755-11-14.

10. Leeb K, Baibergenova A, Wen E, Webster G, Zelmer J. Are there socioeconomic differences in caesarean section rates in Canada? Healthc Policy. 2005;1(1):48-54

11. Merry L, Small R, Blondel B, Gagnon AJ. International migration and caesarean birth: a systematic review and meta-analysis. BMC Pregnancy Childbirth. 2013;13(1):27. https://doi.org/10.1186/1471-2393-13-27.

12. Sdona E, Papamichail D, Ragkou E, Kakalou E, Briana DD, Panagiotopoulos T, Malamitsi-Puchner A. Migration status and perinatal parameters in a Greek public maternity hospital: an illustration of the "healthy immigrant effect". J Matern Fetal Neonatal Med. 2019;32(1):62-6.

13. Stipkova M. Immigrant disadvantage or the healthy immigrant effect? Evidence about low birth weight differences in the Czech Republic. Eur J Pub Health. 2016;26(4):662-6. https://doi.org/10.1093/eurpub/ckw029.

14. Heaman M, Bayrampour H, Kingston D, Blondel B, Gissler M, Roth C, Alexander S, Gagnon A. Migrant women's utilization of prenatal care: a systematic review. Matern Child Health J. 2013;17(5):816-36. https://doi. org/10.1007/s10995-012-1058-z.

15. Rodriguez RL, Elliott MN, Vestal KD, Suttorp MJ, Schuster MA. Determinants of health insurance status for children of Latino immigrant and other US farm workers: findings from the National Agricultural Workers Survey. Arch Pediatr Adolesc Med. 2008;162(12):1175-80. https://doi.org/10.1001/a rchpedi.162.12.1175.

16. Costley PL, East CE. Oxytocin augmentation of labour in women with epidural analgesia for reducing operative deliveries. Cochrane Database Syst Rev. 2013;7:CD009241.

17. Shah RR, Ray JG, Taback N, Meffe F, Glazier RH. Adverse pregnancy outcomes among foreign-born Canadians. J Obstet Gynaecol Can. 2011; 33(3):207-15. https://doi.org/10.1016/S1701-2163(16)34821-6.

18. Zanconato G, lacovella C, Parazzini F, Bergamini V, Franchi M. Pregnancy outcome of migrant women delivering in a public institution in northern Italy. Gynecol Obstet Investig. 2011;72(3):157-62. https://doi.org/10.1159/ 000328318.

19. Gagnon AJ, Van Hulst A, Merry L, George A, Saucier JF, Stanger E, Wahoush $\mathrm{O}$, Stewart DE. Cesarean section rate differences by migration indicators. Arch Gynecol Obstet. 2013;287(4):633-9. https://doi.org/10.1007/s00404012-2609-7.

20. Cheng YM, Yuan W, Cai WD, Zhang WM, Wang TY, Wang Y, Wu SZ, Zhou LF, Luo L, Gao ES. Study on the occurrence of cesarean section (CS) and factors related to CS in China. Zhonghua Liu Xing Bing Xue Za Zhi. 2003; 24(10):893-6.

21. Wang J, Gu S, Ye B, Gao J, Wang F, Dai J, Fu H. The effect of migration and the hukou registration system on psychosocial domains and family functioning of children in Shanghai, China. Int Health. 2019;11(S1):S24-32. https://doi.org/10.1093/inthealth/ihz076.

22. Song Q, Smith JP. Hukou system, mechanisms, and health stratification across the life course in rural and urban China. Health Place. 2019;58:102150. https://doi.org/10.1016/i.healthplace.2019.102150.

23. Zhang J, Geerts C, Hukkelhoven C, Offerhaus P, Zwart J, de Jonge A. Caesarean section rates in subgroups of women and perinatal outcomes. BJOG. 2016;123(5):754-61. https://doi.org/10.1111/1471-0528.13520.

24. Committee Opinion No ACOG. 761: cesarean delivery on maternal request. Obstet Gynecol. 2019;133(1):e73-7.

25. American College of O, Gynecologists: ACOG Committee Opinion No. 386 November 2007. Cesarean delivery on maternal request. Obstet Gynecol. 2007;110(5):1209-12.

26. American College of O, Gynecologists: ACOG committee opinion no. 559 . Cesarean delivery on maternal request. Obstet Gynecol. 2013;121(4):904-7. https://doi.org/10.1097/01.AOG.0000428647.67925.d3.

27. Obstetrics Subgroup CSoO, Gynecology CMA, Obstetrics Subgroup Chinese Society of O, Gynecology Chinese Medical A. The expert consensus on cesarean delivery operation (2014). Zhonghua Fu Chan Ke Za Zhi. 2014; 49(10):721-4.

28. Consultation WHOE. Appropriate body-mass index for Asian populations and its implications for policy and intervention strategies. Lancet. 2004; 363(9403):157-63.
29. Clayton PE, Cianfarani S, Czernichow P, Johannsson G, Rapaport R Rogol A. Management of the child born small for gestational age through to adulthood: a consensus statement of the international societies of pediatric endocrinology and the growth hormone research society. J Clin Endocrinol Metab. 2007;92(3):804-10. https://doi.org/1 $0.1210 / j \mathrm{jc} .2006-2017$

30. Zou G. A modified poisson regression approach to prospective studies with binary data. Am J Epidemiol. 2004;159(7):702-6. https://doi.org/10.1 093/aje/kwh090.

31. Cao Q, Wu Z, Sun Y, Wang T, Han T, Gu C, Sun Y. Application of negative binomial regression and modified Poisson regression in the research of risk factors for injury frequency. Wei Sheng Yan Jiu. 2011; 40(6):702-4 708.

32. Zhang Y, Gu N, Wang Z, Zheng M, Hu Y, Dai Y. Use of the 10-group classification system to analyze how the population control policy change in China has affected cesarean delivery. Int J Gynaecol Obstet. 2017;138(2): 158-63. https://doi.org/10.1002/ijgo.12210.

33. Compilation of main data of population and birth control in Shanghai in 2015 [http://www.wsjsw.gov.cn/wsj/n473/n2413/n2331/u1ai137398.html].

34. Wang X, Hellerstein S, Hou L, Zou L, Ruan Y, Zhang W. Caesarean deliveries in China. BMC Pregnancy Childbirth. 2017;17(1):54. https://doi.org/10.1186/ s1 2884-017-1233-8.

35. Zhang J, Liu Y, Meikle S, Zheng J, Sun W, Li Z. Cesarean delivery on maternal request in Southeast China. Obstet Gynecol. 2008;111(5):1077-82. https://doi.org/10.1097/AOG.0b013e31816e349e.

36. Hua J, Jin H, Gu G, Liu M, Zhang L, Wu Z. The influence of Chinese one-child family status on developmental coordination disorder status. Res Dev Disabil. 2014;35(11):3089-95. https://doi.org/10.1016/j. ridd.2014.07.044.

37. Huesch MD. Association between type of health insurance and elective cesarean deliveries: New Jersey, 2004-2007. Am J Public Health. 2011; 101(11):e1-7. https://doi.org/10.2105/AJPH.2011.300333.

38. Zhu L, Qin M, Du L, Jia W, Yang Q, Walker MC, Wen SW. Comparison of maternal mortality between migrating population and permanent residents in Shanghai, China, 1996-2005. BJOG. 2009;116(3):401-7. https://doi.org/1 0.1111/j.1471-0528.2008.01979.X.

39. Du L, Qin M, Zhang L, Xu H, Zhu L. Trends in maternal mortality in resident vs. migrant women in Shanghai, China, 2000-2009: A register-based analysis. Reprod Health Matters. 2012;20(39):73-80.

40. Zhu L, Tan J, Jia W, Sun X, Cheng X. The effective of pregnancy women at fixed delivery hospital for floating population in Shanghai. Chin Health Resour. 2007:02:89-91.

41. Liu X, Landon MB, Cheng W, Chen Y. Cesarean delivery on maternal request in China: what are the risks and benefits?, Am J Obstet Gynecol. 2015;212(6): 817 e811-9.

42. Sufang G, Padmadas SS, Fengmin Z, Brown JJ, Stones RW. Delivery settings and caesarean section rates in China. Bull World Health Organ. 2007;85(10): 755-62. https://doi.org/10.2471/BLT.06.035808.

43. Bernitz S, Dalbye R, Zhang J, Eggebo TM, Froslie KF, Olsen IC, Blix E, Oian P. The frequency of intrapartum caesarean section use with the WHO partograph versus Zhang's guideline in the labour progression study (LaPS): a multicentre, cluster-randomised controlled trial. Lancet. 2019;393(10169): 340-8. https://doi.org/10.1016/S0140-6736(18)31991-3.

44. Smith V, Gallagher L, Carroll M, Hannon K, Begley C. Antenatal and intrapartum interventions for reducing caesarean section, promoting vaginal birth, and reducing fear of childbirth: an overview of systematic reviews. PLoS One. 2019;14(10):e0224313. https://doi.org/10.1371/journal.pone. 0224313.

45. Zhang $S$, Huang $X$, Tan H. Prenatal anxiety and cesarean section with nonmedical indication. Zhong Nan Da Xue Xue Bao Yi Xue Ban. 2013;38(10): $1070-4$.

46. Wang E. Requests for cesarean deliveries: the politics of labor pain and pain relief in Shanghai, China. Soc Sci Med. 2017;173:1-8. https://doi.org/10.1016/ j.socscimed.2016.11.032.

47. Zhu L, Hua J, Qin M, Dong H, Song J, Xiao L, Yang L, Chen Q. Chen Q: [assessment of effectiveness of natural labor promoting activities in Shanghai]. Matern Child Health Care China. 2014;03:336-8.

\section{Publisher's Note}

Springer Nature remains neutral with regard to jurisdictional claims in published maps and institutional affiliations. 